\title{
NOTICOMUNITARIA
}

\section{Fundación Jorge Otero y María Liévano de Otero, poniéndole el corazón a las niñas de suba}

Karol Guzmán§§§§

La fundación Jorge Otero y María Liévano de Otero, que funciona hace más de 50 años, es una entidad privada, católica, sin ánimo de lucro. Cuenta con dos sedes, una en Bogotá, en la localidad de Suba y otra en Piedecuesta Santander, amparando aproximadamente 300 niñas en edades preescolar y escolar hasta la adolescencia.

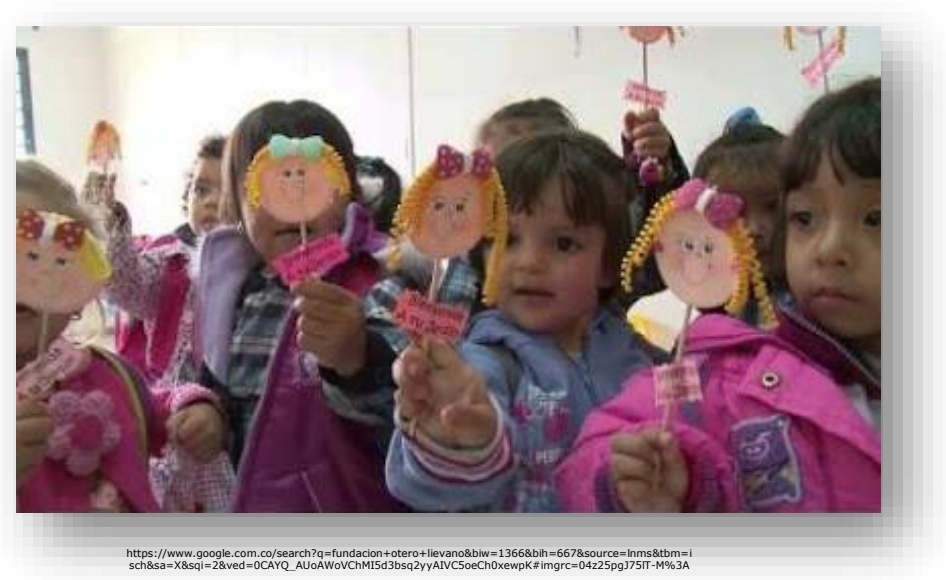

Acoge a niñas con alto riesgo psicosocial, familiar y económico, dándoles un espacio de encuentro, compañía, amor, apoyo, esperanza, ilusión, alegría y protección, durante las horas libres, antes de iniciar o al terminar sus actividades escolares, con el fin, de apoyar su desarrollo integral, formación en valores, principios morales y potenciamiento de sus capacidades.

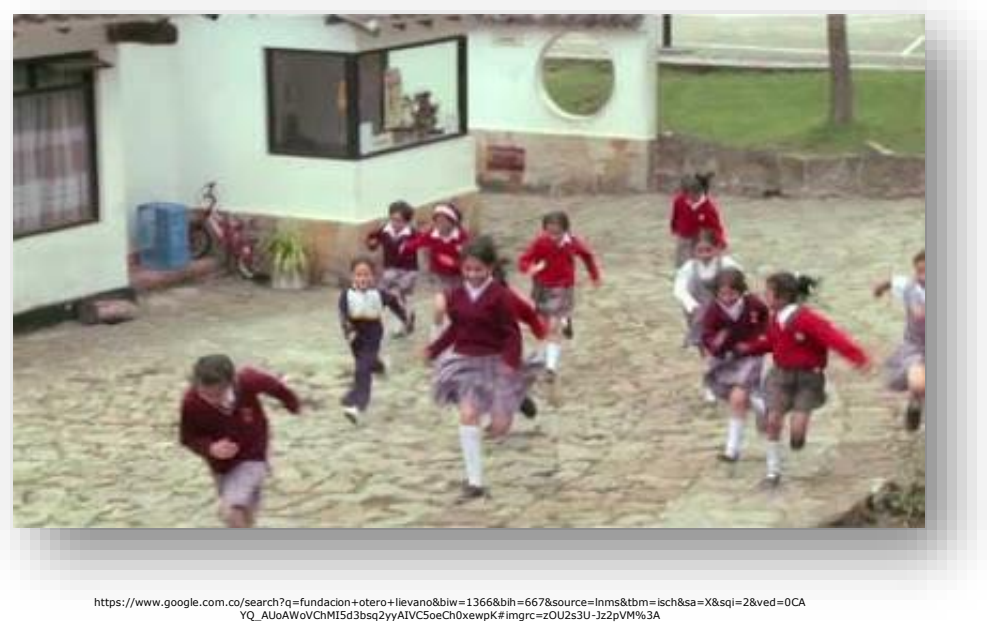

§§§§ MD. Docente Departamento de Medicina Comunitaria - FUJNC * karol.guzman@juanncorpas.edu.co 
Adicionalmente, cuenta con un grupo de profesionales (psicólogos, trabajadores sociales, psicopedagogas y una nutricionista), quienes ofrecen acompañamiento efectivo en las tareas escolares, refuerzo académico, apoyo social y espiritual, fortalecimiento de proyecto de vida, formación en música, danza, deportes y alimentación balanceada.
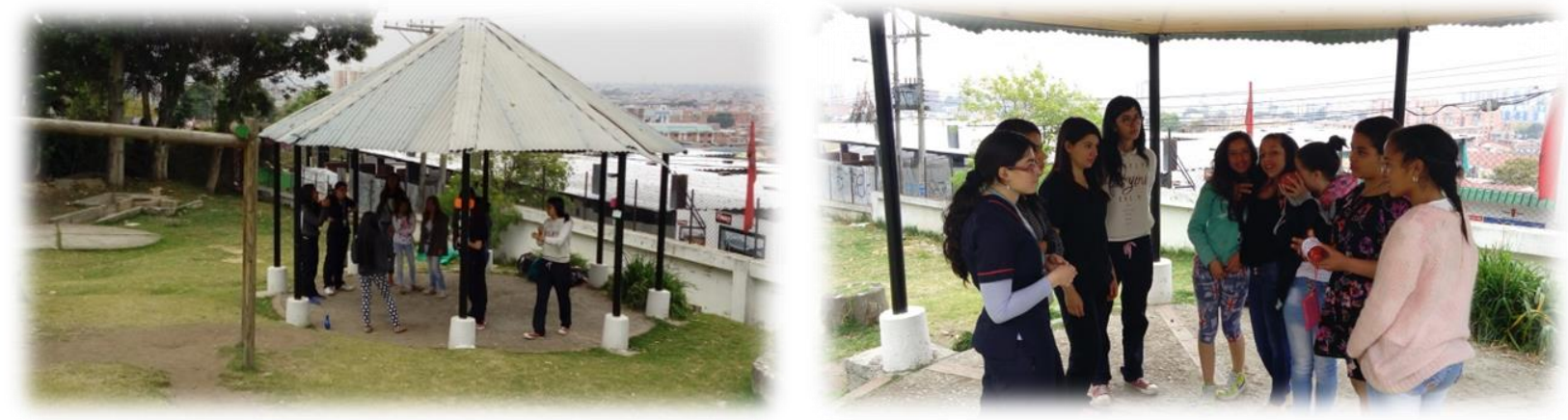

Esta fundación, abre las puertas a la Fundación Universitaria Juan N Corpas mediante un convenio docente asistencial de cooperación mutua, en las secciones de preescolar, primaria y bachillerato, que permite al Departamento de Medicina Comunitaria (Rotación Pediatría Comunitaria) realizar actividades académicas y asistenciales de promoción de la salud y prevención de la enfermedad, tanto a nivel individual como colectivo.
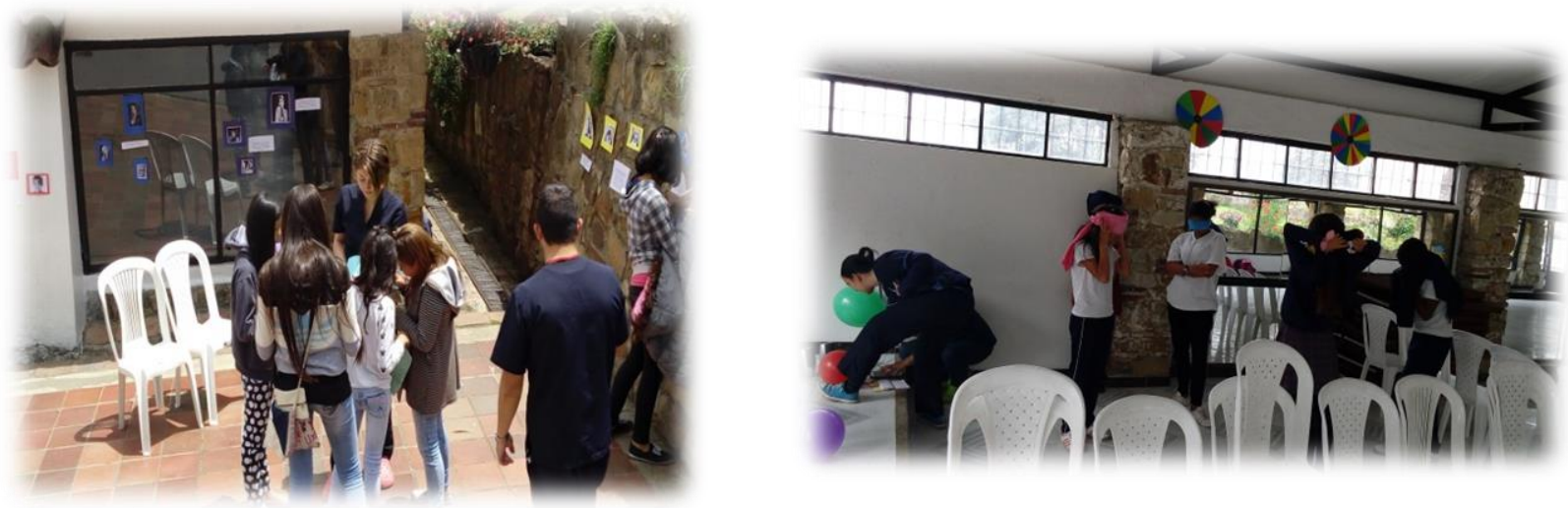

Se realizan actividades de tamizaje nutricional, de malformaciones rotacionales y alteraciones visuales, de neurodesarrollo, así como valoración de factores de riesgo psicosocial y acciones lúdicas con el propósito de la promoción de hábitos de vida saludable y comportamientos resilientes en todos los ciclos vitales que acuden a la fundación.

La fundación nos ha permitido involucrarnos en manejos en múltiples niveles. Las acciones realizadas multi e interdisciplinariamente nos permiten una relación más estrecha con otros perfiles profesionales que buscan como objetivo común el bienestar de las niñas. A niveles transdiciplinarios, se ha logrado realizar acuerdos con los colegios de la localidad y otras instituciones de Suba.

\section{Corpas comprometida con la comunidad!!!}

